administrative block with archive rooms and magazines. The destruction of the building by fire preserved much of its contents: carved furniture, miniature sculpture, seals, decorative stone inlay, pottery and one of the largest collections of cuneiform tablets ever found. The great majority of these tablets are administrative and economic in content but there are also literary compositions, lexical texts, royal edicts and correspondence and treaties. Because of their number and the difficulties posed by the Eblaite language, it will be many years before their publication - entrusted to an international committee - is complete, but preliminary studies provide a foretaste of the rich harvest of information which will eventually be available on the population, economy, institutions, religion, literature and political history of the city.

Any reconstruction of the society and history of Ebla must at this stage be provisional. Matthiae's account, based on the textual evidence available when the 1977 Italian edition went to press, has to a certain extent been amplified and clarified by subsequent research, mainly in the field of linguistics. The population was predominantly but not exclusively Semitic and the closest connections of the Eblaite language are now considered to be with Akkadian, the speech of the Semitic element in the population of Sumer. A considerable amount of information is available on state and municipal administration but there remain many fundamental questions, answers to some of which may not be provided by the type of text found so far. For instance, was kingship hereditary or elective? What proportion of the population was in the service of the state, the temple or large land-owners and under what conditions?

Whether Ebla was the leading state of northern Syria and the centre of an extensive empire, as maintained by Matthiae, requires further investigation, but its conquests included Mari and it was in diplomatic contact with states as far east as the Tigris valley, notably Ashur with which it concluded a commercial treaty. Its far-reaching trading operations are documented by an archive dealing with the state-controlled export of woollen cloth. The destinations of the consignments are distributed over an area extending from Palestine to central Anatolia and from the Mediterranean to Ashur and Kish in northern Sumer. These names of towns and kingdoms provide much new information on political geography but although some are well known, such as Megiddo and Lachish, the majority cannot be located and there are numerous uncertain readings.

The civilization of Early Bronze Age Ebla was formed by the fusion of Syrian and Sumerian cultural traditions. The former are at present most evident in language, religion and architecture; the latter in the use of the cuneiform script, in

literature, art and certain administrative practices. The extent to which political and social institutions were influenced by those of Sumer is not yet clear. Until the lower levels of the site are investigated, the environmental and cultural factors which contributed to the rise of urban life at Ebla must remain a matter of speculation. However, archaic Sumerian elements in the political concepts and art of the palace period suggest that Sumer provided the initial stimulus, probably in the late fourth millennium when it had trading colonies in Syria.

It seems probable that the palace and its archive, which spans the reigns of five kings, was destroyed either by Sargon, founder of the Agade dynasty of Sumer, or by his grandson, Naram-Sin. According to one school of thought, the form of the script employed at Ebla requires the earlier dating. Matthiae prefers the later on the basis of certain artistic features.

The rediscovery of Ebla is of outstanding importance for the early history of civilization in the Near East. The texts and archaeological finds recovered from the palace have revealed the presence in northern Syria in the mid-third millennium of an established urban and literate Semitic society, as advanced as that of contemporary Sumer. The nature of the impact of Sumerian civilization on what was clearly a strong native cultural tradition can already be defined in considerable detail. The texts, when published, will illuminate the history not only of Ebla but also of the numerous states with which it had political and commercial contacts. The significance of the information obtained from Ebla cannot as yet be fully assessed but Matthiae indicates the areas in which it is to be sought.

J. M. Munn-Rankin is a Lecturer in Near Eastern History at the University of Cambridge.

\title{
The appeal of archaeology
}

\section{Gail Kennedy}

The Cambridge Encyclopedia of Archaeology. Edited by Andrew Sherratt. Pp.495. (Cambridge University Press: 1980.) £18.50, $\$ 35$.

THE goal of this handsomely produced volume is to "summarize the present state of knowledge over the whole field of archaeological inquiry',. While The Cambridge Encyclopedia of Archaeology does not quite achieve that somewhat quixotic goal, it does succeed to an impressive degree.

The overall value of the volume, however, rests as much with its clear presentation of the new directions taken by archaeologists since the 1960 s, as with its summarization. In the past most books of this large-format genre have reflected

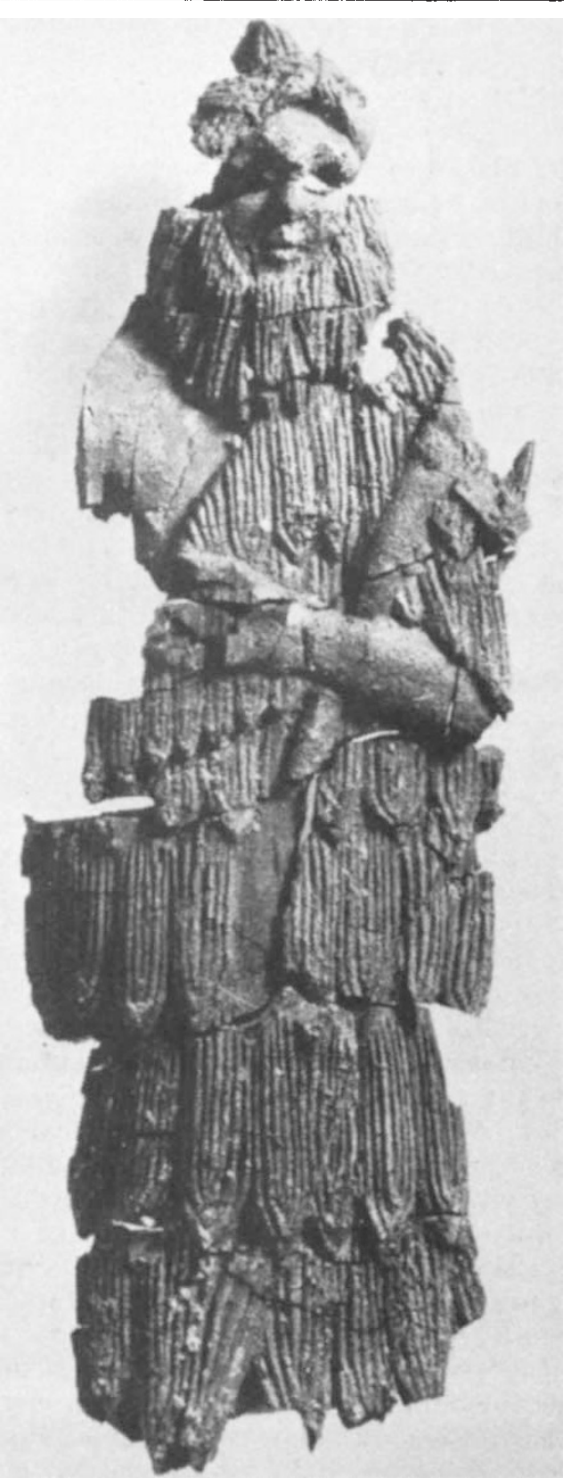

The art of Ebla: wooden figure of a king from Palace G. the earlier emphasis of archaeologists on the exquisitely formed artefact or imaginatively recreated structure; such books have relied more on lavish illustrations and less on informative text. While this volume is indeed well illustrated, the emphasis is on maps and schematic diagrams rather than artefacts, which here are pictured simply and in black and white. The maps - of physical geography, migration patterns, political domains and urban or village street plans - are among the most beautiful and informative in print.

While the maps and diagrams will undoubtedly set a publishing standard for the future, the text is no less attractive and informative. It clearly reflects the trend among archaeologists away from the antiquarian-collector attitudes of the past and 
towards data synthesis, broad regional analyses and model building. It demonstrates clearly that archaeology today is problem-orientated rather than artefactorientated. The problems now under examination by archaeologists of ten centre on the dynamics of interactions between man, his technology and the environment. Systems theory and feedback models provide valuable ways of examining such interactions, and indeed many of the sections in the Encyclopedia are structured either implicitly or explicitly around these conceptual frameworks.

A systems approach becomes a particularly useful tool in archaeology when analysing the emergence of entirely new levels of organization. No longer are such new levels viewed by archaeologists as periods of abrupt revolutionary technological or behavioural change, but instead are seen as periods of adjustment and readjustment to changing configurations of resources and knowledge. The origins of agriculture form one of the more intriguing applications of systems theory. At the end of the last glacial, environmental changes apparently provided both the opportunity and the necessity for the increasingly specialized exploitation of food resources. What is well demonstrated in the chapters on the origins of agriculture in the Near East, Africa and the Far East is that this new and unique strategy for human survival occurred, apparently independently, in several areas. Thus, in each of these major regions, and in at least one centre in the New World, human populations responded to the changing postglacial world in a recurring pattern of increased utilization of a small number of wild foods. It was this emerging dependency on wild foods which led to their ultimate control and domestication. And it was this control over local food resources that paved the way for an increasingly sedentary way of life.

The variety of subjects covered by the book is indeed encyclopaedic. While most of the chapters consist of regional analyses of important phases in human history the origin and development of agriculture, cities and empires, for example - other relevant topics such as early human evolution and dating techniques have not been neglected. The geographical scope, however, is somewhat uneven. Of a total of 64 chapters, only seven (eight if one includes Oceania) are devoted to the archaeological history of the New World. While it may be conceded that the Old World was long the central focus of human development, surely the entire Western Hemisphere merits more discussion than these few rather perfunctory chapters. Moreover, certain major problems in New World prehistory, such as the probable timing and route of human entry, have not even been mentioned.

In the final analysis, the faults of The Cambridge Encyclopedia of Archaeology are few. The short, well-illustrated

chapters are suited for both browsing and more directed reading, while their content will inform all but the specialist. Although price is a drawback, this would be an extremely useful text for broad survey courses in archaeology. The consistent emphasis on method, theory and recent

research, the bibliography and broad geographical and temporal scope all combine to make this a volume with wide appeal.

Gail Kennedy is at the Department of Anthropology, University of California, Los Angeles.

\section{Cancer: how much of a business?}

\section{D.G. Harnden}

The Cancer Syndrome. By Ralph W. Moss. Pp.347. (Grove Press: 1980.) \$12.95, US only.

IT IS usually assumed that those involved in cancer research are motivated by a desire to rid the world of the disease. While this may be partly true, intellectual curiosity and concern for individual patients are often the most potent driving forces. Ralph Moss, however, tells us something different. Cancer research in the USA is, he says, largely manipulated by big business in the hope of financial gain; manipulated by those who believe that a cancer cure will make a fortune for the holder of the patent and by those who fear that preventive measures will involve cleaning up a profitably polluted environment. The medical profession too, he suggests, are part of this conspiracy, favouring treatments which ensure a handsome profit.

It would be easy to dismiss Moss's book as inaccurate in detail and outrageously biased, but to do so would be to fail to acknowledge that some of the criticisms that he makes seem well aimed and that the issues he raises are of considerable importance. Unfortunately, he does not spell out or consider in any constructive way the main issue that he raises, namely "What is the proper relationship between the fundamental discoveries of biological science and the industry that can make these discoveries available to the general public?".

There are two central allegations around which the book is built. First, that orthodox treatment is unsuccessful and that the cancer establishment in the USA will take any steps to ensure that new developments which are not patentable are stifled at birth or as soon thereafter as possible. Second, that little emphasis has been placed on prevention because it would be more profitable to find a patentable cure and because prevention might involve fundamental and expensive alterations in industrial practices.

Is there any truth in either of them? For the commonest cancers it is true that the results of conventional treatment are not good. In breast cancer the five-year survival rate is approximately $50 \%$ (and, as Moss reminds us, five-year survival is not cure), while for lung it is a disasterous $5 \%$. Even worse, neither figure is improving. When we say that improvements have occurred over the past few years it is essentially in cancers that are uncommon, such as Hodgkin's disease and in the childhood neoplasms such as Wilm's tumour. But many cancer patients are cured and many more are given a greatly improved quality of life, so there is, at least, some over-statement. However, when Moss points to over-optimistic propaganda about cures it is hard to disagree with him - we have a long way to go. He therefore suggests that we turn to unorthodox methods such as laetrile, Coley's toxin, hydrazine sulphate and vitamin $C$, and says that information that such methods are already successful has been deliberately suppressed. In a vitriolic attack on the Memorial Sloane Kettering Cancer Centre, the American Cancer Society and the National Institutes of Health, he accuses these institutions and specific individuals of blocking grant awards for research in these areas and of granting awards to others for their help in this process.

As a science writer sacked from the Memorial Sloane Kettering for misrepresenting the work of the Institution, Moss can hardly be without bias - but he is well informed. He shows that the governing bodies of the Memorial Sloane Kettering Cancer Centre and the American Cancer Society have a large representation of those whose business connections could lead to a conflict of interest. Obviously there are altruistic reasons why industrialists and financiers would wish to serve on the board of a cancer centre, but there could be less worthy reasons. Although overt attempts to influence scientific policy would obviously be resisted by the scientific staff, the possibility of indirect influences, especially by those who donate very large sums of money to the institutions, must be a matter for concern. Moss also points to the form of contract between the Memorial Sloane Kettering Cancer Centre and the chemical companies which seems to grant all the advantages to the companies. This is not an easy matter, and the link between industry and the scientist often poses a dilemma. Anyone in cancer research who has a connection with industry is liable to be accused of having compromised his scientific integrity. However, Moss is more concerned with undermining the present structure than with suggesting improvements and the important questions are left unasked. 